\title{
GLOSARIO TERMINOLÓGICO Y FRASEOLÓGICO TRILINGÜE (INGLÉS-FRANCÉS-ESPAÑOL) SOBRE FORMULARIOS DE COOPERACIÓN JUDICIAL INTERNACIONAL EN MATERIA PENAL Iván Delgado Pugés \\ Universidad de Málaga
}

\section{ABSTRACT}

This paper aims to offer a terminological and phraseological compilation, in the form of a trilingual glossary (English-French-Spanish), extracted from the analysis of four forms of international judicial cooperation from the European Judicial Network (namely, European arrest warrant, Request of information extracted from the criminal record, Freezing order, and Model agreement on the establishment of a Joint Investigation Team), as well as a brief preliminary foray into the most common characteristics of this type of documents and of judicial translation.

KEYWORDS: Glossary, Terminology, Phraseology, Form, Judicial Translation, European Judicial Space, European Judicial Network.

\section{RESUMEN}

En el presente artículo pretendemos ofrecer una recopilación terminológica y fraseológica, en forma de glosario trilingüe (inglés-francésespañol), procedente del análisis de cuatro formularios de cooperación judicial internacional de la Red Judicial Europea (Orden Europea de detención y Entrega, Solicitud de antecedentes penales, Orden de embargo y Modelo de acuerdo sobre la Creación de un Equipo de Investigación), así como una breve incursión previa por las características más habituales de este tipo de documentos y de la traducción judicial.

PALABRAS CLAVE: Glosario, Terminología, Fraseología, Formulario, Traducción judicial, Espacio Judicial Europeo, Red Judicial Europea.

\section{INTRODUCCIÓN}

En el artículo que nos ocupa pretendemos poner a disposición de los profesionales de la traducción una recopilación terminológica y fraseológica 
trilingüe (inglés-francés-español) dividida de la siguiente manera: en primer lugar, ofrecemos un glosario que recoge los términos y la fraseología judiciales contenidos en los textos objeto de estudio, que en su totalidad proceden del ámbito del Derecho penal y son de empleo frecuente en la cooperación judicial internacional ${ }^{1}$; y en segundo lugar, presentamos un glosario de términos administrativos. Con objeto de facilitar la búsqueda de los términos por lenguas, ofrecemos el primer glosario - por ser el más extenso- ordenado de forma que se pueda consultar en las tres lenguas de trabajo. Antes de presentarlo, vamos a hacer un breve recorrido preliminar para situar la traducción judicial en su contexto y posteriormente analizaremos someramente qué son los formularios de cooperación judicial internacional que han constituido el corpus textual.

\section{LAS PECULIARIDADES DE LA TRADUCCIÓN JUDICIAL}

Son numerosos los estudios que, en los últimos años, se han ocupado de ir desgranando las características y peculiaridades de la traducción jurídica (Alcaraz Varó: 1994, 2001, 2002; Barceló Martínez, 2010; Bocquet, 2008; Borja Albi: 2000, 2007; Feria González: 1999; Mayoral Asensio: 2003b; San Ginés \& Ortega Arjonilla: 1997, Ortega Arjonilla 2008; Šarčević, 1997; Thiry, 2009). Asimismo, en los últimos años se ha producido un estudio mucho más exhaustivo de la traducción jurada, como ha demostrado Mayoral Asensio (2003a: 457). Sin embargo, la traducción judicial parece no haber despertado el mismo interés que sus «hermanas mayores», puesto que el número de publicaciones específicamente destinadas a su estudio es bastante menor. Ello quizá se deba a la confusión existente en torno a la distinción conceptual de estos tres tipos de traducción (jurídica, jurada y judicial), que ha sido tratada y aclarada por Ortega Arjonilla (2005) y Lobato Patricio (2009). Según el primero de estos dos investigadores, la traducción judicial «es aquella que se lleva a cabo por iniciativa de una entidad, institución o persona autorizada (Tribunal, juez, policía)». El ejercicio profesional de la traducción judicial, al igual que la traducción jurada, requiere el respeto escrupuloso de un conjunto de normas

\footnotetext{
${ }_{1}^{1}$ Según el Prontuario de Auxilio Judicial Internacional (actualizado a 26 de julio de 2007 en su parte penal) editado por el Ministerio de Justicia, el auxilio judicial internacional penal «comprende, por un lado, los procedimientos de extradición y, por otro, el llamado auxilio judicial secundario o comisiones rogatorias, que consiste en la realización de cualesquiera actos de instrucción en el marco de una investigación o procedimiento judicial penal. En cuanto a la ejecución de sentencias penales, se alude tanto al traslado de personas condenadas, como al reconocimiento y ejecución de resoluciones firmes de condena dictadas por otro Estado».
} 
deontológicas $^{2}$, entre las que podríamos citar que el traductor judicial debe ser merecedor de la confianza de todos los participantes en el proceso judicial, esto es, debe dar una imagen de honestidad, imparcialidad, discreción y competencia, e intentará lograr la mayor objetividad posible mediante el respeto al texto, sin caer deliberadamente en un sentido u otro. La traducción judicial se asemeja a la traducción jurídica en dos aspectos: comparte la naturaleza jurídica de determinados documentos y utiliza también formularios en versiones multilingües. Empero, haremos especial hincapié en las diferencias que la convierten en un tipo de traducción propia. Mayoral Asensio (2004) apunta, a este respecto, que «cualquier actividad humana puede verse involucrada en un proceso jurídico (piénsese en sentencias, contratos, legislación, etc.) y formar parte de los contenidos de un texto a priori considerado como jurídico». Así pues, cualquier documento susceptible de verse incluido en el sumario de un proceso judicial es objeto de traducción judicial. De esta forma, documentos de índole personal (diarios, cartas, notas), informes periciales o informes técnicos se incorporan al ámbito de la traducción judicial. Esto propicia la aparición frecuente de documentos escritos en muy diversos registros de lengua, sin tener que estar redactados en un registro culto. Alcaraz Varó y Hughes (2002: 14) lo ilustran magníficamente:

But in dealing with texts concerned with court proceedings translators will often face a considerable mixture of styles and registers. There is the legalese of the professional lawyers, the everyday language of lay witnesses and litigants, the slang of the police and the criminal underworld and the often extremely technical jargon of the reports and testimony of expert witnesses who may be doctors, surgeons, forensic pathologists, bankers, brokers, architects, builders, technicians, engineers or members of any profession whatever, depending on the facts of the case.

Otra característica diferenciadora de la traducción judicial es que:

a) Todos los documentos judiciales traducidos comprometen legalmente al autor de la traducción (al igual que sucede en la traducción jurada). Pueden, llegado el caso, ser objeto de denuncia y de reparación por vía judicial.

\footnotetext{
2 Si se desea ahondar en el estudio de las implicaciones que tiene la deontología en el ejercicio de la traducción jurídica, jurada y judicial, el lector interesado puede acudir a: LOBATO PATRICIO, Julia (2008): Aspectos deontológicos y profesionales de la traducción jurídica, jurada y judicial. Málaga, Servicio de Publicaciones e Intercambio Científico [CD-ROM].
} 
b) Todos los documentos judiciales traducidos requieren siempre la presencia del documento original para ser considerados válidos. Incluso en determinadas ocasiones el traductor puede ser citado para que comparezca ante el tribunal y dé cuentas de las decisiones de traducción tomadas ${ }^{3}$. No obstante, los documentos jurídicos que se «corredactan» en las instituciones internacionales —siendo la Unión Europea una de ellas — no están supeditados a la presencia del TO, pues todos los textos son considerados originales ${ }^{4}$.

Por lo tanto, los documentos que son objeto de la traducción judicial no tienen que ser necesariamente de naturaleza jurídica. Sin embargo, los formularios que hemos analizado con vistas a la extracción de su terminología y fraseología sí serán de índole jurídica.

\section{LOS FORMULARIOS DE COOPERACIÓN JUDICIAL EN MATERIA PENAL}

Se denomina formulario a una plantilla o página con espacios vacíos que han de ser rellenados con alguna finalidad. La mayoría de los instrumentos de la Unión Europea van acompañados de formularios normalizados destinados a facilitar la comprensión mutua por parte de emisor y receptor.

Según el informe Hacia una estrategia europea en materia de e-Justicia, de 30 de mayo de 2008, con objeto de mejorar la eficacia de la cooperación judicial, los formularios deben poder ser objeto de una traducción automática completa, es decir, no sólo en lo que se refiere a su marco, sino también a su contenido. Se sistematizará el recurso a «formularios dinámicos», que utilizarán segmentos de texto y la terminología preestablecidos, para transmitir con rapidez solicitudes o información en todas las lenguas de la UE.

Los formularios que hemos analizado para extraer la terminología y fraseología que mostramos en el glosario presentan las características de ser textos altamente especializados, por lo que el nivel o estrato de comunicación especializada (relación emisor-receptor) se dará entre especialistas en el tema.

Siguiendo a Mayoral Asensio (1997), podemos afirmar que los formularios presentan dos clases de información:

\footnotetext{
3 Un ejemplo reciente tuvo lugar durante el macrojuicio por los atentados del 11 de marzo de 2004 en Madrid, en cuyo transcurso el Presidente de la Sala de lo Penal de la Audiencia Nacional, Javier Gómez Bermúdez, requirió la comparecencia de los dos intérpretes del juicio en su despacho el 15 de febrero de 2007.

[www.elpais.com/articulo/opinion/Respeto/interpretes/elpepiopi/20070323elpepiopi_7/Tes] ${ }_{4}$ En algunas ocasiones no se consideran originales todos los textos y se establece un valor jerárquico de los mismos, siendo determinadas versiones las originales.
} 
- Lo común a todos los documentos del mismo uso

- Lo particular

La información común sería aquella contenida en el formulario o impreso antes de ser rellenado, mientras que la información particular sería la que, una vez cumplimentada, aparezca reflejada en cada caso concreto. Así pues, según este autor, «los documentos a los que nos referimos [los formularios] son únicos en cuanto a la información particular, pero son múltiples en cuanto a la información general o común, respondiendo a un modelo textual establecido». De esta forma, señala que:

Desde el punto de vista de la traducción, la gran originalidad de muchos de estos documentos [los formularios] reside $[\ldots]$ en la existencia de sus partes comunes que, en una situación ideal, harían que sólo fuera necesario traducirlas una vez por un solo traductor para cubrir todas las necesidades de todos los traductores que se enfrentaran al mismo tipo de texto.

Debido a la existencia todos estos modelos de formularios que deben ser idénticos en todas las lenguas en cuanto a su contenido jurídico - pues nos enfrentamos ante un derecho comunitario-, Mayoral Asensio (1997) insiste en la convergencia o armonización de los documentos que sirven de soporte a las relaciones jurídicas internacionales. Este proceso tendrá una serie de consecuencias, especialmente a nivel terminológico, como también apunta:

Esta tendencia conduce a una normalización jurídica que desemboca en normalización terminológica y, en última instancia, en la edición de documentos bilingües o multilingües. Son numerosos los tipos de documentos que están redactados en varias lenguas, y todo parece indicar que este sistema se va a generalizar en la medida de lo posible. [...] Los documentos multilingües hacen innecesaria la repetición de la traducción para cada caso.

Javier L. Parra (2008: 727) precisa que, en el ámbito de la Cooperación judicial en materia penal, estos formularios están más desarrollados en su vertiente civil que penal, lo que supone un aliciente más para que se realicen trabajos en este campo:

Se trata de una herramienta [los formularios] que se encuentra mucho más desarrollada por la RJECM que en la penal, así los formularios civiles se adaptan plenamente a los modelos 
publicados por los Reglamentos comunitarios, por lo que se permite la traducción automática y autorizada de los campos oficiales del formulario - no así de contenido-. Por el contrario, el producto homólogo de la RJE penal [...] se encuentra todavía en fase de desarrollo y el formulario de solicitud de asistencia judicial penal se ofrece de forma voluntaria a los operadores judiciales.

\subsection{Formularios OBJEto DE ANÁlisis (I): LA ORDEN EuropeA DE DETENCIÓN Y ENTREGA 5}

La Orden Europea de Detención y Entrega (también conocida como «Euroorden») fue aprobada por la Decisión marco 2002/584/JHA del Consejo de 13 de junio de 2002 (Diario Oficial de las Comunidades Europeas L 190, 18.07.2002) a propuesta de la Comisión Europea. Su objetivo consiste en reemplazar los largos procedimientos de extradición dentro del territorio de la UE a través de un procedimiento judicial mejorado y simplificado de entrega de personas a la hora de interponer una acción judicial penal (entrega para investigación o enjuiciamiento) o ejecutar una pena o medida privativa de libertad o auto de internamiento.

Fue el primer instrumento que se adoptó de acuerdo con el principio de reconocimiento mutuo de resoluciones judiciales y de confianza, en virtud del cual los Estados Miembros no pueden invocar la prohibición de entrega de un nacional, lo que supone un antes y un después en el proceso de construcción del espacio judicial europeo.

Se trata de un título judicial unificado para los Estados miembros de la Unión Europea, pues simplemente se debe cumplimentar un formulario incorporado a la propia Ley o a la Decisión-marco del Consejo de 13 de junio de 2002 (relativa a la orden de detención europea y los procedimientos de entrega entre Estados miembros), sin necesidad de presentar ninguna otra documentación adicional. La legislación del Estado de ejecución es necesaria para conocer los medios de transmisión que acepta: por ejemplo, si es posible enviarla a través de SIRENE ${ }^{6}$ o si se exige la documentación original, el idioma y plazo en que ha de remitirse una vez sea detenida la persona buscada, etc.

\footnotetext{
5 Este formulario se denomina «European Arrest Warrant» en inglés y «Mandat d'arrêt européen» en francés.

${ }^{6}$ La Oficina SIRENE es una oficina policial desde la que se introducen en el Sistema de Información Schengen (SIS) las reclamaciones de personas en el Espacio Schengen, así como las Órdenes de Detención Europea. Sirve también para el intercambio electrónico de huellas y fotografías a efectos de identificación.
} 
La Euroorden tiene unos plazos muy breves de tramitación, decisión y entrega (si hay consentimiento el plazo de decisión es de 10 días y en caso contrario, el plazo es de 60 días, prorrogables excepcionalmente por otros 30 más). Según la Ley, «El Juzgado Central de Instrucción, como autoridad judicial de ejecución española, comprobará que la orden europea esté traducida al español. En el supuesto de que no se remita la orden traducida, la autoridad judicial de ejecución española lo comunicará a la autoridad judicial de emisión, al objeto de que la remita en el más breve plazo. El procedimiento se suspenderá hasta tanto no se reciba la misma».

\subsection{Formularios ObJETO DE ANÁLISIS (II): LA SOliCITUd DE ANTECEDENTES PENALES $^{7}$}

El antecedente penal es una circunstancia consistente en haber sido alguien anteriormente condenado u objeto de persecución penal, y queda anotado en un registro público o en los archivos policiales (dependiendo de la legislación del Estado miembro). Como explica Dueñas Jiménez (2006: 3):

Cada vez parece más evidente y clara, especialmente en los últimos años, la necesidad de que los Estados Miembros compartan información sobre los delitos cometidos y sus autores. Muchos de los defectos en la prevención delictiva se han debido a la falta de intercambio de información operativa. Resulta por ello fundamental arbitrar algún sistema de intercambio de información sobre los procesos penales en curso, pero algunos Estados Miembros carecen aún de registros en este ámbito.

Tras sopesar cómo solucionar esta situación ${ }^{8}$, se ha optado por mantener el actual sistema de registros penales y crear entre ellos un sistema de interconexión, una red de transmisión segura de información (llamada red TESTA $\left.^{9}\right)$. Imaginemos que un fiscal español solicita información sobre una persona de nacionalidad francesa. Se dirige directamente al registro de antecedentes penales español, donde, mediante esta red de comunicación, envía

\footnotetext{
7 Este formulario se denomina «Request for information extracted from the criminal record» en inglés y «Demande d'informations extraites du casier judiciaire» en francés.

${ }^{8}$ Una de las soluciones propuestas fue la creación de un registro centralizado de antecedentes penales a nivel europeo con sede en Bruselas o Luxemburgo), desechada por su coste económico y la falta de una infraestructura y medios materiales y personales.

9 Según el documento La construcción de los servicios pan-europeos de Administración electrónica (2007: 26), «La red TESTA es una red IP aislada de Internet que interconecta las redes administrativas de los Estados miembros y de las Instituciones y Agencias europeas».
} 
una solicitud de información al registro francés, que a su vez lo enviará al registro español, y éste la transmitirá al fiscal que inició el proceso.

\subsection{Formularios OBJETO DE ANÁLISIS (III): LA ORDEN DE EMBARGO10}

El embargo es la «retención, traba o secuestro de bienes por mandamiento de un juez o la autoridad competente» (DRAE). A raíz de una iniciativa de Bélgica, Francia y Suecia, el Consejo adoptó en 2003 la Decisión marco 2003/577/JAI del Consejo, de 22 de julio de 2003, relativa a la ejecución en la Unión Europea de las resoluciones de embargo preventivo de bienes y de aseguramiento de pruebas. Esta iniciativa tiene por objeto establecer las normas mediante las cuales un Estado miembro reconoce y ejecuta en su territorio una resolución de embargo preventivo de bienes dictada por una autoridad judicial de otro Estado miembro en el marco de un procedimiento penal. Por embargo preventivo de bienes se entiende, según esta Decisión marco, «cualquier medida adoptada por una autoridad judicial de un Estado miembro con el fin de impedir la destrucción, la transformación, el desplazamiento, etc. de un bien». Los elementos de prueba son los objetos, documentos o datos que puedan tener carácter probatorio en un proceso penal.

Según la Decisión, el Estado miembro en el que una autoridad judicial haya dictado, validado o confirmado una resolución de embargo preventivo de bienes o de aseguramiento de pruebas se denomina «Estado de emisión»y aquel Estado miembro en cuyo territorio se halle el bien o elemento de prueba se denomina «Estado de ejecución».

3.3. Formularios objeto de ANÁlisis (IV): EL MODELO DE ACUERDO SOBRE LA CREACIÓN DE UN EQUIPO CONJUNTO DE INVESTIGACIÓN ${ }^{11}$

El 13 de junio de 2002 el Consejo aprobó la Decisión marco 2002/465/JAI relativa a los equipos conjuntos de investigación. Hace 10 años, en la reunión de los Estados miembros en la ciudad de Tampere, éstos se habían formulado la promesa de crear equipos conjuntos de investigación para luchar contra el tráfico de drogas, la trata de seres humanos y el terrorismo. El Convenio relativo a la asistencia judicial en materia penal que se adoptó en mayo de 2000 prevé la creación de equipos conjuntos de investigación. Debido a la tardanza de los Estados miembros para ratificar el Convenio, en junio de

\footnotetext{
${ }^{10}$ Este formulario se denomina «Freezing Order» en inglés y «Décision de gel» en francés.

${ }^{11}$ Este formulario se denomina «Model agreement on the establishment of a Joint Investigation Team» en inglés y «Modèle d'accord pour la création d'une Équipe commune d'enquête» en francés.
} 
ENTREC ULTURAS Número 2. ISSN: 1989-5097. Fecha de publicación: 27-12-2010

2002 el Consejo adoptó la Decisión marco 2002/465/JAI, que dejó de ser aplicable cuando entró en vigor, el 23 de agosto de 2005, el Convenio de 2000 sobre ayuda mutua judicial en materia penal entre los Estados miembros de la Unión Europea.

Este acuerdo permite, con el fin de realizar investigaciones penales en los Estados miembros que requieran una acción coordinada y concertada, la creación de un Equipo Conjunto de Investigación por parte de un mínimo de dos Estados miembros. A tal efecto, las autoridades competentes de los Estados miembros interesados celebrarán un acuerdo común en el que se tendrán que definir las modalidades del Equipo Conjunto de Investigación.

\section{GLOSARIO TERMINOLÓGICO Y FRASEOLÓGICO}

\subsection{GLOSARIO DE TÉRMINOS Y FRASEOLOGÍA JUDICIALES (INGLÉS-FRANCÉS- ESPAÑOL)}

\begin{tabular}{|c|c|c|}
\hline INGLÉS & FRANCÉS & ESPAÑOL \\
\hline Abovementioned person & Personne susmentionnée & Persona mencionada \\
\hline Agreement & Acuerdo & Accord \\
\hline Arson & Incendie volontaire & Incendio voluntario \\
\hline Beneficial owner & Propriétaire connu & Beneficiario efectivo \\
\hline Bona fide & De bonne foi & De buena fe \\
\hline By virtue of & En vertu de & En virtud de \\
\hline Central authority & Autorité centrale & Autoridad central \\
\hline Certificate & Certificat & Certificado \\
\hline Code & Code & Código \\
\hline Competence & Compétence & Competencia \\
\hline Computer-related crime & Cybercriminalité & Delito informático \\
\hline Confiscation order & Décision de confiscation & Resolución de decomiso \\
\hline Contact person & Personne à contacter & Persona de contacto \\
\hline Convention & Convention & Convenio \\
\hline Convicted person & Personne condamnée & Persona condenada \\
\hline Conviction & Condamnation & Condena \\
\hline Corruption & Corruption & Corrupción \\
\hline $\begin{array}{l}\text { Counterfeiting and piracy } \\
\text { of products }\end{array}$ & $\begin{array}{l}\text { Contrefaçon et piratage de } \\
\text { produits }\end{array}$ & $\begin{array}{l}\text { Violación de derechos de } \\
\text { propiedad industrial y } \\
\text { falsificación de mercancías }\end{array}$ \\
\hline Counterfeiting of currency & Faux monnayage & Falsificación de moneda \\
\hline Court & Cour & Tribunal \\
\hline Criminal proceedings & Procédure pénale & Procesos penales \\
\hline Criminal prosecution & Poursuite pénale & Enjuiciamiento criminal \\
\hline $\begin{array}{l}\text { Custodial life sentence or } \\
\text { Lifetime detention order }\end{array}$ & $\begin{array}{l}\text { Peine ou mesure de sûreté } \\
\text { privatives de liberté à }\end{array}$ & $\begin{array}{lccc}\text { Pena o } & \text { medida } & \text { de } \\
\text { seguridad } & \text { privativas } & \text { de } \\
\end{array}$ \\
\hline
\end{tabular}


ENTREC ULTURAS Número 2. ISSN: 1989-5097. Fecha de public a ción: 27-12-2010

\begin{tabular}{|c|c|c|}
\hline & caractère perpétuel & $\begin{array}{lll}\begin{array}{l}\text { libertad de carácter } \\
\text { perpetuo }\end{array} & \\
\end{array}$ \\
\hline Custody & Garde & Custodia \\
\hline Data protection rules & $\begin{array}{l}\text { Reglès particulières en } \\
\text { matière de protection des } \\
\text { données }\end{array}$ & $\begin{array}{l}\text { Normas específicas de } \\
\text { protección de datos }\end{array}$ \\
\hline Decision & Décision & Decisión \\
\hline $\begin{array}{lll}\begin{array}{l}\text { Decision } \\
\text { absentia }\end{array} & \text { rendered in } \\
\end{array}$ & Décision rendue par défaut & $\begin{array}{l}\text { Resolución dictada en } \\
\text { rebeldía }\end{array}$ \\
\hline Detention order & $\begin{array}{l}\text { Mésure de sûreté privative } \\
\text { de liberté }\end{array}$ & $\begin{array}{l}\text { Medida de seguridad } \\
\text { privativa de libertad }\end{array}$ \\
\hline Done at & Fait à & Hecho en \\
\hline DNA profile & Profil ADN & Caracterización del ADN \\
\hline Enforceable judgement & Jugement exéc & Sentencia ejecutiva \\
\hline Enforcement & Exécution & Ejecución \\
\hline Entry into force & Entrée en vigueur & Entrada en vigor \\
\hline Enviromental crime & $\begin{array}{l}\text { Crimes } \\
\text { l'environnement }\end{array}$ & $\begin{array}{l}\text { Delitos contra el medio } \\
\text { ambiente }\end{array}$ \\
\hline Eur & & Eur \\
\hline European arrest warrant & Mandat d'arrêt européen & $\begin{array}{lll}\begin{array}{l}\text { Orden de detención } \\
\text { europea }\end{array} & \\
\end{array}$ \\
\hline European Communities & $\mathrm{s}$ & Comunidades europeas \\
\hline European judicial network & Iropéen & Red Judicial Europea \\
\hline Europol & Eur & Europol \\
\hline $\begin{array}{l}\text { Execution of a custodial } \\
\text { sentence }\end{array}$ & Exécution d'une peine & Ejecución de una pena \\
\hline Expiry date & Fecha de expiración & - \\
\hline Extraterritorality & Extraterritorialité & Extraterritorialidad \\
\hline $\begin{array}{l}\text { Facilitation } \\
\text { unauthorised entry and } \\
\text { residence }\end{array}$ & $\begin{array}{l}\text { Aide à l'entrée et au séjour } \\
\text { irrégulier }\end{array}$ & $\begin{array}{l}\text { Ayuda a la entrada y } \\
\text { residencia en situación } \\
\text { ilegal }\end{array}$ \\
\hline Financial interests & nanciers & Intereses financieros \\
\hline Fingerprints & e digitale & Impresiones dactilares \\
\hline Form & & dario \\
\hline $\begin{array}{l}\text { Forgery of administrative } \\
\text { documents and trafficking } \\
\text { therein }\end{array}$ & $\begin{array}{l}\text { Falsification de documents } \\
\text { administratifs et traffic de } \\
\text { faux }\end{array}$ & $\begin{array}{l}\text { Falsificación de } \\
\text { documentos } \\
\text { administrativos y tráfico de } \\
\text { documentos falsos }\end{array}$ \\
\hline $\begin{array}{l}\text { Forgery of means of } \\
\text { payment }\end{array}$ & $\begin{array}{l}\text { Falsification de moyens de } \\
\text { paiement }\end{array}$ & $\begin{array}{l}\text { Falsificación de medios de } \\
\text { pago }\end{array}$ \\
\hline Framework Decision & Décision-cadre & Decisión marco \\
\hline Freezing order & Décision de gel & Orden de embargo \\
\hline Fraud & Fraude & Fraude \\
\hline General conditions & Conditions générales & Condiciones generales \\
\hline
\end{tabular}


ENTRECULTURAS Número 2. ISSN: 1989-5097. Fecha de public a ción: 27-12-2010

\begin{tabular}{|c|c|c|}
\hline Grievous bodily injury & Coups et blessures graves & $\begin{array}{lll}\begin{array}{l}\text { Agresión con lesiones } \\
\text { graves }\end{array} & \\
\end{array}$ \\
\hline Hearing & Audience & Vista \\
\hline Hereafter & Ci-après & A continuación \\
\hline Hereinafter & Ci-après & En lo sucesivo \\
\hline Hereto & À la présente & - \\
\hline Holder & Détenteur & Titular \\
\hline Hostage taking & Prise d'otage & Toma de rehenes \\
\hline $\begin{array}{ll}\text { International Criminal } \\
\text { Court }\end{array}$ & Cour pénale internationale & Corte Penal Internacional \\
\hline Judicial authority & Autorité judiciaire & Autoridad judicial \\
\hline $\begin{array}{l}\text { Judicial decision having } \\
\text { the same effect }\end{array}$ & $\begin{array}{l}\text { Décision judiciaire ayant la } \\
\text { même force }\end{array}$ & $\begin{array}{l}\text { Resolución judicial } \\
\text { ejecutiva del igual fuerza }\end{array}$ \\
\hline Jurisdiction & Juridiction & Jurisdicción \\
\hline Illegal restraint & Séquestration & Detención ilegal \\
\hline $\begin{array}{l}\text { Illicit trade in human } \\
\text { organs and tissue }\end{array}$ & $\begin{array}{l}\text { Trafic illicite d'organes et } \\
\text { de tissues humains }\end{array}$ & $\begin{array}{l}\text { Tráfico ilícito de órganos y } \\
\text { tejidos humanos }\end{array}$ \\
\hline $\begin{array}{l}\text { Illicit trafficking in cultural } \\
\text { goods }\end{array}$ & $\begin{array}{l}\text { Trafic illicite de biens } \\
\text { culturels }\end{array}$ & $\begin{array}{l}\text { Tráfico ilícito de bienes } \\
\text { culturales }\end{array}$ \\
\hline $\begin{array}{l}\text { Illicit trafficking in } \\
\text { endangered animal species } \\
\text { and endangered plant } \\
\text { species and varieties }\end{array}$ & $\begin{array}{l}\text { Trafic illicite d'espèces } \\
\text { animales menacées et } \\
\text { d'espèces et d'essences } \\
\text { végétales menacées }\end{array}$ & $\begin{array}{l}\text { Tráfico ilícito de especies } \\
\text { animales protegidas y de } \\
\text { especies y variedades } \\
\text { vegetales protegidas }\end{array}$ \\
\hline $\begin{array}{l}\text { Illicit trafficking in } \\
\text { hormonal substances and } \\
\text { other growth promoters }\end{array}$ & $\begin{array}{l}\text { Trafic illicite de substances } \\
\text { hormonales et autres } \\
\text { facteurs de croissance }\end{array}$ & $\begin{array}{l}\text { Tráfico ilícito de sustancias } \\
\text { hormonales y otros } \\
\text { factores de crecimiento }\end{array}$ \\
\hline $\begin{array}{l}\text { Illicit trafficking in } \\
\text { narcotic drugs and } \\
\text { psychotropic substances }\end{array}$ & $\begin{array}{l}\text { Trafic illicite de stupéfiants } \\
\text { et de substances } \\
\text { psychotropes }\end{array}$ & $\begin{array}{l}\text { Tráfico ilícito de } \\
\text { estupefacientes y sustancias } \\
\text { psicotrópicas }\end{array}$ \\
\hline $\begin{array}{l}\text { Illicit trafficking in nuclear } \\
\text { or radioactive materials }\end{array}$ & $\begin{array}{l}\text { Trafic illicite de matières } \\
\text { nucléaires et radioactives }\end{array}$ & $\begin{array}{l}\text { Tráfico ilícito de materiales } \\
\text { radioactivos o sustancias } \\
\text { nucleares }\end{array}$ \\
\hline $\begin{array}{l}\text { Illicit trafficking in } \\
\text { weapons, munitions and } \\
\text { explosives }\end{array}$ & $\begin{array}{l}\text { Trafic illicite d'armes, de } \\
\text { munitions et d'explosifs }\end{array}$ & $\begin{array}{l}\text { Tráfico ilícito de armas, } \\
\text { municiones y explosivos }\end{array}$ \\
\hline In accordance with & Conformément à & $\begin{array}{l}\text { De conformidad con } \\
\text { Con arreglo a } \\
\text { De acuerdo con }\end{array}$ \\
\hline Information & Renseignement & Información \\
\hline Issuing Member State & État membre d'émission & Estado miembro emisor \\
\hline Kidnapping & Enlèvement & Secuestro \\
\hline $\begin{array}{l}\text { Laundering of } \\
\text { proceeds of crime }\end{array}$ & $\begin{array}{l}\text { Blanchiment du produit du } \\
\text { crime }\end{array}$ & $\begin{array}{l}\text { Blanqueo de los productos } \\
\text { del delito }\end{array}$ \\
\hline Legal assistance & Assistance juridique & Asistencia jurídica \\
\hline
\end{tabular}


ENTREC ULTURAS Número 2. ISSN: 1989-5097. Fecha de public ación: 27-12-2010

\begin{tabular}{|c|c|c|}
\hline Legal classification & Qualification légale & Tipificación legal \\
\hline Legal guarantees & Garanties juridiques & Garantías jurídicas \\
\hline Legal person & Personne morale & Persona jurídica \\
\hline Legal remedies & Voies de recours & Vías de recurso \\
\hline Legal system & Système juridique & Ordenamiento jurídico \\
\hline Length of the sentence & Durée de la peine & Duración de la pena \\
\hline Letter of request & Commission rogatoire & Comisión rogatoria \\
\hline Liaison officers & Officiers de liaison & Funcionarios de enlace \\
\hline Measures of clemency & Mesures de clémence & Medidas de clemencia \\
\hline Member State & État membre & Estado miembro \\
\hline Murder & Homicide volontaire & Homicidio voluntario \\
\hline Mutual assistance & Asistencia judicial & Entraide judiciaire \\
\hline Mutual consent of & - & Consentimiento mutuo de \\
\hline National register number & $\begin{array}{lll}\text { Numéro au registre } \\
\text { national }\end{array}$ & $\begin{array}{l}\text { Número del documento } \\
\text { nacional de identidad }\end{array}$ \\
\hline Natural person & Personne physique & Persona física \\
\hline Offence & Infraction & Infracción \\
\hline Office accommodation & Bureaux & $\begin{array}{ll}\begin{array}{l}\text { Locales } \\
\text { oficinas }\end{array} & \text { destinados } \\
\end{array}$ \\
\hline Official stamp & Cachet officiel & Sello oficial \\
\hline On secondment from & Détaché par & $\begin{array}{l}\text { En comisión de servicios } \\
\text { de }\end{array}$ \\
\hline Optional information & Informations facultatives & Información facultativa \\
\hline $\begin{array}{l}\text { Organisational } \\
\text { arrangements }\end{array}$ & $\begin{array}{lll}\text { Dispositions relatives à } \\
\text { l'organisation }\end{array}$ & $\begin{array}{l}\text { Disposiciones en materia } \\
\text { de organización }\end{array}$ \\
\hline $\begin{array}{l}\text { Organised or armed } \\
\text { robbery }\end{array}$ & $\begin{array}{l}\text { Vols organisés ou avec } \\
\text { arme }\end{array}$ & $\begin{array}{l}\text { Robos organizados o a } \\
\text { mano armada }\end{array}$ \\
\hline Participating officials & Agents participant & Funcionarios participantes \\
\hline $\begin{array}{l}\text { Participation in a criminal } \\
\text { organisation }\end{array}$ & $\begin{array}{l}\text { Participation à une } \\
\text { organisation criminelle }\end{array}$ & $\begin{array}{ll}\text { Pertenencia a una } \\
\text { organización delictiva }\end{array}$ \\
\hline Parties & Personnes & Partes \\
\hline Parties to the agreement & Parties à l'accord & $\begin{array}{l}\text { Partes en el acuerdo } \\
\text { Partes del acuerdo }\end{array}$ \\
\hline Practice & Pratique & Práctica \\
\hline Proceeds & Produits du crime & Productos del delito \\
\hline Proprio motu & De sa propre initiative & Motu proprio \\
\hline Protocol & Protocole & Protocolo \\
\hline Punishable offences & Infractions punies & Infracciones castigadas \\
\hline Racism & Racisme & Racismo \\
\hline $\begin{array}{l}\text { Racketeering } \\
\text { extortion }\end{array}$ & $\begin{array}{l}\text { Racket et extorsion de } \\
\text { fonds }\end{array}$ & $\begin{array}{l}\text { Chantaje y extorsión de } \\
\text { fondos }\end{array}$ \\
\hline Rape & Viol & Violación \\
\hline Registered seat & Siège statutaire & Sede registral \\
\hline Regulation & Réglementation & Disposición reglamentaria \\
\hline
\end{tabular}


ENTRECULTURAS Número 2. ISSN: 1989-5097. Fecha de public a ción: 27-12-2010

\begin{tabular}{|c|c|c|}
\hline $\begin{array}{l}\text { Remaining sentence to be } \\
\text { served }\end{array}$ & Peine restant à purger & Pena que resta por cumplir \\
\hline Reply to the request & è la demande & Respuesta a la solicitud \\
\hline Representative & Représentant & Representante \\
\hline $\begin{array}{l}\text { Representative of the } \\
\text { competent authority }\end{array}$ & $\begin{array}{l}\text { Représentant de l'autorité } \\
\text { compétente }\end{array}$ & $\begin{array}{l}\text { Representante de } \\
\text { autoridad competente }\end{array}$ \\
\hline $\begin{array}{l}\text { Request for information } \\
\text { extracted from the } \\
\text { criminal record }\end{array}$ & $\begin{array}{l}\text { Demande d'informations } \\
\text { extraites du casier judiciare }\end{array}$ & $\begin{array}{l}\text { Solicitud de antecedentes } \\
\text { penales }\end{array}$ \\
\hline Requesting State & État & quirente \\
\hline Review & & \\
\hline Sabotage & & \\
\hline Securing evidence & Con & miento de pruebas \\
\hline $\begin{array}{l}\text { Seizure and handing over } \\
\text { of property }\end{array}$ & Saisie et remise d'objets & $\begin{array}{l}\text { Intervención y entrega de } \\
\text { objetos }\end{array}$ \\
\hline greement & Accord séparé & Acuerdo separado \\
\hline Serious crime & $\begin{array}{lll}\begin{array}{l}\text { Formes } \\
\text { criminalité }\end{array} & \text { graves de } \\
\end{array}$ & $\begin{array}{l}\text { Formas gaves } \\
\text { delincuencia }\end{array}$ \\
\hline $\begin{array}{l}\text { Sexual exploitation of } \\
\text { children and child } \\
\text { pornography }\end{array}$ & $\begin{array}{l}\text { Exploitation sexuelle des } \\
\text { enfants } \\
\text { pédopornographie }\end{array}$ & $\begin{array}{l}\text { Explotación sexual de los } \\
\text { niños y pornografía infantil }\end{array}$ \\
\hline hen apply & & aplicación \\
\hline Social security number & Numéro de securité sociale & $\begin{array}{l}\text { Número de seguridad } \\
\text { social }\end{array}$ \\
\hline victions & ondamnations & Relación de condenas \\
\hline provision & statutaire & \\
\hline Subje & - & \\
\hline Sub & ultérieure & \\
\hline equest & $\begin{array}{lll}\text { ation de la } \\
\text { le }\end{array}$ & Presentación de la solicitud \\
\hline Sus: & e soupçonnée & $\mathrm{Pc}$ \\
\hline Swir & & \\
\hline Terr & $\mathrm{Te}$ & $\mathrm{Te}$ \\
\hline To accept a proposal & Accepter une proposition & Aceptar una propuesta \\
\hline To adopt a provision & Adopter une disposition & Adoptar una disposición \\
\hline To arrest & & \\
\hline To carry o & ne mission & Llevar a cabo una tarea \\
\hline To carry out an operation & Mener une opération & $\begin{array}{lll}\text { Llevar a cabo una } \\
\text { actuación }\end{array}$ \\
\hline To commit an offence & Commettre une infraction & Cometer una infracción \\
\hline $\begin{array}{l}\text { To conclude an agreement } \\
\text { on }\end{array}$ & Conclure un accord pour & Celebrar un acuerdo sobre \\
\hline To confer a right & Conférer un droit & Conferir un derecho \\
\hline To decide by common & Décider d'un & Decidir de común acuerdo \\
\hline
\end{tabular}


ENTRECULTURAS Número 2. ISSN: 1989-5097. Fecha de public ación: 27-12-2010

\begin{tabular}{|c|c|c|}
\hline agreement & accord & \\
\hline To give one's consent & Donner son consentement & Dar el consentimiento \\
\hline To inform by letter & Notifier par une lettre & Notificar por carta \\
\hline To issue (a warrant) & Émettre (un mandat) & Dictar (una orden) \\
\hline $\begin{array}{l}\text { To participate in a } \\
\text { criminal investigation }\end{array}$ & $\begin{array}{l}\text { Participer à une enquête } \\
\text { pénale }\end{array}$ & $\begin{array}{l}\text { Participar en } \\
\text { investigación penal }\end{array}$ \\
\hline To request & Demander & Solicitar \\
\hline To request a proposal & Demander une proposition & Solicitar una propuesta \\
\hline To submit an appeal & Introduire un recours & Presentar un recurso \\
\hline To summon & Citer & Citar \\
\hline To surrender & Re & En \\
\hline $\begin{array}{l}\text { Trafficking in human } \\
\text { beings }\end{array}$ & Traite des êtres humains & Trata de seres humanos \\
\hline $\begin{array}{l}\text { Trafficking in stolen } \\
\text { vehicles }\end{array}$ & Trafic de véhicules volés & $\begin{array}{l}\text { Tráfico de vehículos } \\
\text { robados }\end{array}$ \\
\hline Transfer of evidence & $\begin{array}{l}\text { Remise des éléments de } \\
\text { preuve }\end{array}$ & Traslado de pruebas \\
\hline $\begin{array}{l}\text { Transmission and } \\
\text { administrative reception }\end{array}$ & $\begin{array}{l}\text { Transmission et réception } \\
\text { administrative }\end{array}$ & $\begin{array}{l}\text { Transmisión y recepción } \\
\text { administrativas }\end{array}$ \\
\hline Treaty & Traité & Tratado \\
\hline Under the Law & En vertu du droit & Con arreglo a Derecho \\
\hline Undersigned authority & Autorité soussignée & Autoridad abajo firmante \\
\hline $\begin{array}{l}\text { Unlawful seizure of } \\
\text { Aircraft/ships }\end{array}$ & $\begin{array}{l}\text { Détournement } \\
\text { d'avion/navire }\end{array}$ & $\begin{array}{l}\text { Secuestro de aeronaves y } \\
\text { buques }\end{array}$ \\
\hline Within the framework of & Dans le cadre de & En el marco de \\
\hline Xenophobia & Xénophobie & Xenofobia \\
\hline
\end{tabular}

4.2. GLOSARIO DE TÉRMINOS Y FRASEOLOGÍA JUDICIALES (FRANCÉS-INGLÉSESPAÑOL)

\begin{tabular}{|l|l|l|}
\hline \multicolumn{1}{|c|}{ FRANCÉS } & \multicolumn{1}{c|}{ INGLÉS } & \multicolumn{1}{c|}{ ESPAÑOL } \\
\hline À la présente & Hereto & Aceptar una propuesta \\
\hline Accepter une proposition & To accept a proposal & Acuerdo \\
\hline Accord & Agreement & Acuerdo separado \\
\hline Accord séparé & Separate agreement & Adoptar una disposición \\
\hline Adopter une disposition & To adopt a provision & Funcionarios participantes \\
\hline Agents participant & Participating officials & Detener \\
\hline Arrêter & To arrest & Asistencia jurídica \\
\hline Assistance juridique & Legal assistance & Vista \\
\hline Audience & Hearing & Autoridad abajo firmante \\
\hline Autorité soussignée & Undersigned authority & Autoridad central \\
\hline Autorité centrale & Central authority & Autoridad judicial \\
\hline Autorité judiciaire & Judicial authority & \\
\hline
\end{tabular}


ENTRECULTURAS Número 2. ISSN: 1989-5097. Fecha de public a ción: 27-12-2010

\begin{tabular}{|c|c|c|}
\hline $\begin{array}{l}\text { Aide à l'entrée et au } \\
\text { séjour irrégulier }\end{array}$ & $\begin{array}{l}\text { Facilitation } \\
\text { unauthorised entry and } \\
\text { residence }\end{array}$ & $\begin{array}{l}\text { Ayuda a la entrada y } \\
\text { residencia en situación ilegal }\end{array}$ \\
\hline Bureaux & Office accommodation & $\begin{array}{lll}\text { Locales destinados a } \\
\text { oficinas }\end{array}$ \\
\hline Cachet officiel & Official stamp & Sello oficial \\
\hline Certificat & Certificate & Certificado \\
\hline Ci-après & $\begin{array}{l}\text { Hereafter } \\
\text { Hereinafter }\end{array}$ & $\begin{array}{l}\text { A continuación } \\
\text { En lo sucesivo }\end{array}$ \\
\hline Citer & To summon & Citar \\
\hline Code & Code & Código \\
\hline Commettre une infraction & To commit an offence & Cometer una infracción \\
\hline Commission rogatoire & Letter of request & Comisión rogatoria \\
\hline $\begin{array}{l}\text { Communautés } \\
\text { européennes }\end{array}$ & European Communities & Comunidades europeas \\
\hline Compétence & Competence & Competencia \\
\hline Conclure un accord pour & $\begin{array}{l}\text { To conclude an agreement } \\
\text { on }\end{array}$ & Celebrar un acuerdo sobre \\
\hline Condamnation & Conviction & Condena \\
\hline Conditions générales & General conditions & Condiciones generales \\
\hline Conférer un droit & To confer a right & Conferir un derecho \\
\hline Confiscation ultérieure & Subsequent confiscation & Decomiso posterior \\
\hline Conformément à & In accordance with & $\begin{array}{l}\text { De conformidad con } \\
\text { Con arreglo a } \\
\text { De acuerdo con }\end{array}$ \\
\hline $\begin{array}{l}\text { Contrefaçon et piratage } \\
\text { de produits }\end{array}$ & $\begin{array}{l}\text { Counterfeiting and piracy } \\
\text { of products }\end{array}$ & $\begin{array}{l}\text { Violación de derechos de } \\
\text { propiedad industrial y } \\
\text { falsificación de mercancías }\end{array}$ \\
\hline Convention & Convention & Convenio \\
\hline Cour & Court & Tribunal \\
\hline Cour pénale internationale & $\begin{array}{l}\text { International Criminal } \\
\text { Court }\end{array}$ & Corte Penal Internacional \\
\hline Corruption & Corruption & Corrupción \\
\hline $\begin{array}{ll}\text { Crimes } & \text { contre } \\
\text { l'environnement } & \\
\end{array}$ & Enviromental crime & $\begin{array}{l}\text { Delitos contra el medio } \\
\text { ambiente }\end{array}$ \\
\hline Cybercriminalité & Computer-related crime & Delito informático \\
\hline Dans le cadre de & Within the framework of & En el marco de \\
\hline De bonne foi & Bona fide & De buena fe \\
\hline De sa propre initiative & Proprio motu & Motu proprio \\
\hline $\begin{array}{l}\text { Décider d'un commun } \\
\text { accord }\end{array}$ & $\begin{array}{l}\text { To decide by common } \\
\text { agreement }\end{array}$ & Decidir de común acuerdo \\
\hline Décision & Decision & Decisión \\
\hline Décision-cadre & Framework Decision & Decisión marco \\
\hline Décision de confiscation & Confiscation order & Resolución de decomiso \\
\hline Décision de gel & Freezing order & Orden de embargo \\
\hline
\end{tabular}


ENTREC ULTURAS Número 2. ISSN: 1989-5097. Fecha de public a ción: 27-12-2010

\begin{tabular}{|c|c|c|}
\hline $\begin{array}{l}\text { Décision judiciaire ayant } \\
\text { la même force }\end{array}$ & $\begin{array}{l}\text { Judicial decision having } \\
\text { the same effect }\end{array}$ & $\begin{array}{l}\text { Resolución judicial ejecutiva } \\
\text { del igual fuerza }\end{array}$ \\
\hline $\begin{array}{l}\text { Décision rendue par } \\
\text { défaut }\end{array}$ & $\begin{array}{l}\text { Decision rendered in } \\
\text { absentia }\end{array}$ & $\begin{array}{lll}\text { Resolución dictada en } \\
\text { rebeldía }\end{array}$ \\
\hline $\begin{array}{lcr}\text { Demande } & \text { d'informations } \\
\text { extraites } & \text { du } & \text { casier } \\
\text { judiciare } & & \\
\end{array}$ & $\begin{array}{l}\text { Request for information } \\
\text { extracted from the } \\
\text { criminal record }\end{array}$ & $\begin{array}{l}\text { Solicitud de antecedentes } \\
\text { penales }\end{array}$ \\
\hline Demander & To request & Solicitar \\
\hline $\begin{array}{l}\text { Demander } \\
\text { proposition }\end{array}$ & To request a proposal & Solicitar una propuesta \\
\hline Détache par & On secondment from & En comisión de servicios de \\
\hline Détenteur & Holder & Titular \\
\hline $\begin{array}{l}\text { Détournement } \\
\text { d'avion/navire }\end{array}$ & $\begin{array}{l}\text { Unlawful seizure of } \\
\text { Aircraft/ships }\end{array}$ & $\begin{array}{l}\begin{array}{l}\text { Secuestro de aeronaves y } \\
\text { buques }\end{array} \\
\end{array}$ \\
\hline Disposition statutaire & Statutory provision & Disposición legal \\
\hline $\begin{array}{ll}\text { Dispositions relatives à } \\
\text { l'organisation }\end{array}$ & $\begin{array}{l}\text { Organisational } \\
\text { arrangements }\end{array}$ & $\begin{array}{l}\text { Disposiciones en materia de } \\
\text { organización }\end{array}$ \\
\hline Durée de la peine & Length of the sentence & Duración de la pena \\
\hline Effectuer une mission & To carry out a task & Llevar a cabo una tarea \\
\hline Émettre (un mandat) & To issue (a warrant) & Dictar (una orden) \\
\hline Empreinte digitale & Fingerprints & Impresiones dactilares \\
\hline En vertu de & By virtue of & En virtud de \\
\hline En vertu du droit & Under the Law & Con arreglo a Derecho \\
\hline Enlèvement & Kidnapping & Secuestro \\
\hline Entraide judiciaire & Mutual assistance & Asistencia judicial \\
\hline Entrée en vigueur & Entry into force & Entrada en vigor \\
\hline État membre & Member State & Estado miembro \\
\hline État membre d'émission & Issuing Member State & Estado miembro emisor \\
\hline État requérant & Requesting State & Estado requirente \\
\hline Escroquerie & Swindling & Estafa \\
\hline Eurojust & Eurojust & Eurojust \\
\hline Europol & Europol & Europol \\
\hline Exécution & Enforcement & Ejecución \\
\hline Exécution d'une peine & $\begin{array}{l}\text { Execution of a custodial } \\
\text { sentence }\end{array}$ & Ejecución de una pena \\
\hline Extraterritorialité & Extraterritorality & Extraterritorialidad \\
\hline Fait à & Done at & Hecho en \\
\hline $\begin{array}{lll}\begin{array}{l}\text { Formes } \\
\text { criminalité }\end{array} & \text { graves de } \\
\end{array}$ & Serious crime & $\begin{array}{ll}\text { Formas gaves } \\
\text { delincuencia }\end{array}$ \\
\hline Formulaire & Form & Formulario \\
\hline Jugement exécutoire & Enforceable judgement & Sentencia ejecutiva \\
\hline Juridiction & Jurisdiction & Jurisdicción \\
\hline $\begin{array}{l}\text { Falsification de } \\
\text { documents administratifs } \\
\text { et traffic de faux }\end{array}$ & $\begin{array}{l}\text { Forgery of administrative } \\
\text { documents and trafficking } \\
\text { therein }\end{array}$ & $\begin{array}{l}\text { Falsificación de documentos } \\
\text { administrativos y tráfico de } \\
\text { documentos falsos }\end{array}$ \\
\hline
\end{tabular}


ENTREC ULTURAS Número 2. ISSN: 1989-5097. Fecha de public ación: 27-12-2010

\begin{tabular}{|c|c|c|}
\hline $\begin{array}{l}\text { Falsification de moyens } \\
\text { de paiement }\end{array}$ & $\begin{array}{l}\text { Forgery of means of } \\
\text { payment }\end{array}$ & $\begin{array}{l}\text { Falsificación de medios de } \\
\text { pago }\end{array}$ \\
\hline Faux monnayage & Counterfeiting of currency & Falsificación de moneda \\
\hline Garanties juridiques & Legal guarantees & Garantías jurídicas \\
\hline Homicide volontaire & Murder & Homicidio voluntario \\
\hline Incendie volontaire & Arson & Incendio voluntario \\
\hline Informations facultatives & Optional information & Información facultativa \\
\hline Infraction & Offence & Infracción \\
\hline Infractions punies & Punishable offences & Infracciones castigadas \\
\hline Intérêts financiers & Financial interests & Intereses financieros \\
\hline Introduire un recours & To submit an appeal & Presentar un recurso \\
\hline $\begin{array}{l}\text { Mésure de sûreté privative } \\
\text { de liberté }\end{array}$ & Detention order & $\begin{array}{l}\text { Medida de seguridad } \\
\text { privativa de libertad }\end{array}$ \\
\hline Notifier par une lettre & To inform by letter & Notificar por carta \\
\hline $\begin{array}{l}\text { Numéro au registre } \\
\text { national }\end{array}$ & National register number & $\begin{array}{l}\text { Número del documento } \\
\text { nacional de identidad }\end{array}$ \\
\hline $\begin{array}{l}\text { Numéro de securité } \\
\text { sociale }\end{array}$ & Social security number & Número de seguridad social \\
\hline Officiers de liaison & Liaison officers & Funcionarios de enlace \\
\hline $\begin{array}{l}\text { Participation à une } \\
\text { organisation criminelle }\end{array}$ & $\begin{array}{l}\text { Participation in a criminal } \\
\text { organisation }\end{array}$ & $\begin{array}{ll}\text { Pertenencia a a } & \text { una } \\
\text { organización delictiva } & \\
\end{array}$ \\
\hline $\begin{array}{l}\text { Participer à une enquête } \\
\text { pénale }\end{array}$ & $\begin{array}{l}\text { To participate in a } \\
\text { criminal investigation }\end{array}$ & $\begin{array}{l}\text { Participar en una } \\
\text { investigación penal }\end{array}$ \\
\hline Parties à l'accord & Parties to the agreement & $\begin{array}{l}\text { Partes en el acuerdo } \\
\text { Partes del acuerdo }\end{array}$ \\
\hline $\begin{array}{l}\text { Peine ou mesure de sûreté } \\
\text { privatives de liberté à } \\
\text { caractère perpétuel }\end{array}$ & $\begin{array}{l}\text { Custodial life sentence or } \\
\text { Lifetime detention order }\end{array}$ & $\begin{array}{l}\text { Pena o medida de seguridad } \\
\text { privativas de libertad de } \\
\text { carácter perpetuo }\end{array}$ \\
\hline Peine restant à purger & $\begin{array}{l}\text { Remaining sentence to be } \\
\text { served }\end{array}$ & Pena que resta por cumplir \\
\hline Personne à contacter & Contact person & Persona de contacto \\
\hline Personne condamnée & Convicted person & Persona condenada \\
\hline Personne morale & Legal person & Persona jurídica \\
\hline Personne physique & Natural person & Persona física \\
\hline Personne susmentionnée & Abovementioned person & Persona mencionada \\
\hline Personne soupçonnée & Suspected person & Persona sospechosa \\
\hline Personnes & Parties & Partes \\
\hline Poursuite pénale & Criminal prosecution & Enjuiciamiento criminal \\
\hline Pratique & Practice & Práctica \\
\hline $\begin{array}{l}\text { Présentation de la } \\
\text { demande }\end{array}$ & Submission of request & Presentación de la solicitud \\
\hline Prise d'otage & Hostage taking & Toma de rehenes \\
\hline Procédure pénale & Criminal proceedings & Procesos penales \\
\hline Produits du crime & Proceeds & Productos del delito \\
\hline Protocole & Protocol & Protocolo \\
\hline
\end{tabular}


ENTREC ULTURAS Número 2. ISSN: 1989-5097. Fecha de public ación: 27-12-2010

\begin{tabular}{|c|c|c|}
\hline Qualification légale & Legal classification & Tipificación legal \\
\hline Racisme & Racism & Racismo \\
\hline $\begin{array}{l}\text { Racket et extorsion de } \\
\text { fonds }\end{array}$ & $\begin{array}{l}\text { Racketeering } \\
\text { extortion }\end{array}$ & $\begin{array}{l}\text { Chantaje y extorsión de } \\
\text { fondos }\end{array}$ \\
\hline Référence du dossier & File reference & Referencia del expediente \\
\hline $\begin{array}{l}\text { Reglès particulières en } \\
\text { matière de protection des } \\
\text { données }\end{array}$ & Data protection rules & $\begin{array}{l}\text { Normas específicas de } \\
\text { protección de datos }\end{array}$ \\
\hline Réglementation & Regulation & Disposición reglamentaria \\
\hline Remettre & To surrender & Entregar \\
\hline $\begin{array}{l}\text { Remise des éléments de } \\
\text { preuve }\end{array}$ & Transfer of evidence & Traslado de pruebas \\
\hline Renseignement & Information & Información \\
\hline Réponse à la demande & Reply to the request & Respuesta a la solicitud \\
\hline Représentant & Representative & Representante \\
\hline $\begin{array}{l}\text { Représentant de l'autorité } \\
\text { compétente }\end{array}$ & $\begin{array}{l}\text { Representative of the } \\
\text { competent authority }\end{array}$ & $\begin{array}{l}\text { Representante de } \\
\text { autoridad competente }\end{array}$ \\
\hline $\begin{array}{ll}\text { Réseau } & \text { judiciaire } \\
\text { européen } & \end{array}$ & European judicial network & Red Judicial Europea \\
\hline $\begin{array}{ll}\begin{array}{l}\text { Revevé } \\
\text { condamnations }\end{array} & \text { des } \\
\end{array}$ & Statement of convictions & Relación de condenas \\
\hline Révision & Review & Revisar \\
\hline Sabotage & Sabotage & Sabotaje \\
\hline Saisie et remise d'objets & $\begin{array}{l}\text { Seizure and handing over } \\
\text { of property }\end{array}$ & $\begin{array}{l}\text { Intervención y entrega de } \\
\text { objetos }\end{array}$ \\
\hline Séquestration & Illegal restraint & Detención ilegal \\
\hline Sera applicable & Shall then apply & Será de aplicación \\
\hline Siège statutaire & Registered seat & Sede registral \\
\hline Système juridique & Legal system & Ordenamiento jurídico \\
\hline Terrorisme & Terrorism & Terrorismo \\
\hline Trafic de véhicules volés & $\begin{array}{l}\text { Trafficking in stolen } \\
\text { vehicles }\end{array}$ & $\begin{array}{l}\text { Tráfico de vehículos } \\
\text { robados }\end{array}$ \\
\hline $\begin{array}{l}\text { Trafic illicite d'armes, de } \\
\text { munitions et d'explosifs }\end{array}$ & $\begin{array}{l}\text { Illicit trafficking in } \\
\text { weapons, munitions and } \\
\text { explosives }\end{array}$ & $\begin{array}{l}\text { Tráfico ilícito de armas, } \\
\text { municiones y explosivos }\end{array}$ \\
\hline $\begin{array}{l}\text { Trafic illicite de biens } \\
\text { culturels }\end{array}$ & $\begin{array}{l}\text { Illicit trafficking in cultural } \\
\text { goods }\end{array}$ & $\begin{array}{l}\text { Tráfico ilícito de bienes } \\
\text { culturales }\end{array}$ \\
\hline $\begin{array}{l}\text { Trafic illicite d'espèces } \\
\text { animales menacées et } \\
\text { d'espèces et d'essences } \\
\text { végétales menacées }\end{array}$ & $\begin{array}{l}\text { Illicit trafficking in } \\
\text { endangered animal species } \\
\text { and endangered plant } \\
\text { species and varieties }\end{array}$ & $\begin{array}{l}\text { Tráfico ilícito de especies } \\
\text { animales protegidas y de } \\
\text { especies y variedades } \\
\text { vegetales protegidas }\end{array}$ \\
\hline $\begin{array}{l}\text { Trafic illicite de matières } \\
\text { nucléaires et radioactives }\end{array}$ & $\begin{array}{l}\text { Illicit trafficking in nuclear } \\
\text { or radioactive materials }\end{array}$ & $\begin{array}{l}\text { Tráfico ilícito de materiales } \\
\text { radioactivos o sustancias } \\
\text { nucleares }\end{array}$ \\
\hline Trafic illicite d'organes et & Illicit trade in human & Tráfico ilícito de órganos y \\
\hline
\end{tabular}


ENTREC ULTURAS Número 2. ISSN: 1989-5097. Fecha de public a ción: 27-12-2010

\begin{tabular}{|c|c|c|}
\hline de tissues humains & organs and tissue & tejidos humanos \\
\hline $\begin{array}{lcr}\text { Trafic } & \text { illicite } & \text { de } \\
\text { stupéfiants } & \text { et } & \text { de } \\
\text { substances } & \text { psychotropes }\end{array}$ & $\begin{array}{l}\text { Illicit trafficking in } \\
\text { narcotic drugs and } \\
\text { psychotropic substances }\end{array}$ & $\begin{array}{l}\text { Tráfico ilícito de } \\
\text { estupefacientes y sustancias } \\
\text { psicotrópicas }\end{array}$ \\
\hline $\begin{array}{l}\text { Trafic illicite de } \\
\text { substances hormonales et } \\
\text { autres facteurs de } \\
\text { croissance }\end{array}$ & $\begin{array}{l}\text { Illicit trafficking in } \\
\text { hormonal substances and } \\
\text { other growth promoters }\end{array}$ & $\begin{array}{l}\text { Tráfico ilícito de sustancias } \\
\text { hormonales y otros factores } \\
\text { de crecimiento }\end{array}$ \\
\hline Traité & Tre & \\
\hline Traite des êtres humains & $\begin{array}{l}\text { Trafficking in human } \\
\text { beings }\end{array}$ & Trata de seres humanos \\
\hline $\begin{array}{l}\text { on et réception } \\
\text { ive }\end{array}$ & $\begin{array}{l}\text { mission and } \\
\text { aistrative reception }\end{array}$ & $\begin{array}{l}\text { ión y recepción } \\
\text { rativas }\end{array}$ \\
\hline Viol & Rape & \\
\hline Voies de & Legal & Irso \\
\hline $\begin{array}{l}\text { Vols organisés ou avec } \\
\text { arme }\end{array}$ & $\begin{array}{l}\text { Organised } \\
\text { robbery }\end{array}$ & $\begin{array}{l}\text { Robos organizados o a } \\
\text { mano armada }\end{array}$ \\
\hline Xénophobie & Xenophobia & Xenofobia \\
\hline
\end{tabular}

4.3. GLOSARIO DE TÉRMINOS Y FRASEOLOGÍA JUDICIALES (ESPAÑOL-INGLÉSFRANCÉS)

\begin{tabular}{|l|l|l|}
\hline \multicolumn{1}{|c|}{ EsPAÑOL } & \multicolumn{1}{|c|}{ INGLÉS } & \multicolumn{1}{c|}{ FRANCÉS } \\
\hline A continuación & Hereafter & Ci-après \\
\hline Aceptar una propuesta & To accept a proposal & Accepter une proposition \\
\hline Acuerdo & Agreement & Accord \\
\hline Acuerdo separado & Separate agreement & Accord séparé \\
\hline Adoptar una disposición & To adopt a provision & Adopter une disposition \\
\hline $\begin{array}{l}\text { Agresión con lesiones } \\
\text { graves }\end{array}$ & Grievous bodily injury & Coups et blessures graves \\
\hline Aseguramiento de pruebas & Securing evidence & Constitution de preuve \\
\hline Asistencia judicial & Mutual assistance & Entraide judiciaire \\
\hline Asistencia jurídica & Legal assistance & Assistance juridique \\
\hline Autoridad abajo firmante & Undersigned authority & Autorité soussignée \\
\hline Autoridad central & Central authority & Autorité centrale \\
\hline Autoridad judicial & Judicial authority & Autorité judiciaire \\
\hline $\begin{array}{l}\text { Ayuda a la entrada y } \\
\text { residencia en situación ilegal }\end{array}$ & $\begin{array}{l}\text { Facilitation } \\
\text { unauthorised entry and } \\
\text { residence }\end{array}$ & $\begin{array}{l}\text { Aide à l'entrée et au séjour } \\
\text { irrégulier }\end{array}$ \\
\hline Beneficiario efectivo & Beneficial owner & Propriétaire connu \\
\hline $\begin{array}{l}\text { Blanqueo de los productos } \\
\text { del delito }\end{array}$ & $\begin{array}{l}\text { Laundering of the } \\
\text { proceeds of crime }\end{array}$ & $\begin{array}{l}\text { Blanchiment du produit du } \\
\text { crime }\end{array}$ \\
\hline $\begin{array}{l}\text { Caracterización del ADN } \\
\text { Dertificado profile }\end{array}$ & Profil ADN \\
\hline
\end{tabular}


ENTREC ULTURAS Número 2. ISSN: 1989-5097. Fecha de public ación: 27-12-2010

\begin{tabular}{|c|c|c|}
\hline $\begin{array}{l}\text { Chantaje y extorsión de } \\
\text { fondos }\end{array}$ & $\begin{array}{l}\text { Racketeering } \\
\text { extortion }\end{array}$ & $\begin{array}{l}\text { Racket et extorsion de } \\
\text { fonds }\end{array}$ \\
\hline Citar & To summon & Citer \\
\hline Código & Code & Code \\
\hline Cometer una infracción & To commit an offence & Commettre une infraction \\
\hline Comisión rogatoria & Letter of request & Commission rogatoire \\
\hline Competencia & Competence & Compétence \\
\hline Comunidades europeas & European Communities & $\begin{array}{l}\text { Communautés } \\
\text { européennes }\end{array}$ \\
\hline Con arreglo a & In accordance with & Conformément à \\
\hline Con arreglo a Derecho & Under the Law & En vertu du droit \\
\hline Condena & Conviction & Condamnation \\
\hline Condiciones generales & General conditions & Conditions générales \\
\hline Conferir un derecho & To confer a right & Conférer un droit \\
\hline Consentimiento mutuo de & Mutual consent of & - \\
\hline Convenio & Convention & Convention \\
\hline Corte Penal Internacional & $\begin{array}{l}\text { International Criminal } \\
\text { Court }\end{array}$ & Cour pénale internationale \\
\hline Corrupción & Corruption & Corruption \\
\hline Custodia & Custody & Garde \\
\hline Dar el consentimiento & To give one's consent & Donner son consentement \\
\hline De acuerdo a & In accordance with & Conformément à \\
\hline De buena fe & Bona fide & De bonne foi \\
\hline De conformidad con & In accordance with & Conformément à \\
\hline Decidir de común acuerdo & $\begin{array}{l}\text { To decide by common } \\
\text { agreement }\end{array}$ & $\begin{array}{l}\text { Décider d'un commun } \\
\text { accord }\end{array}$ \\
\hline Decisión & Decision & Décision \\
\hline Decisión marco & Framework Decision & Décision-cadre \\
\hline Decomiso posterior & Subsequent confiscation & Confiscation ultérieure \\
\hline Delito informático & Computer-related crime & Cybercriminalité \\
\hline $\begin{array}{l}\text { Delitos contra el medio } \\
\text { ambiente }\end{array}$ & Enviromental crime & $\begin{array}{l}\text { Crimes } \\
\text { l'environnement }\end{array}$ \\
\hline Detención ilegal & Illegal restraint & Séquestration \\
\hline Detener & To arrest & Arrêter \\
\hline Dictar (una orden) & To issue (a warrant) & Émettre (un mandat) \\
\hline $\begin{array}{l}\text { Disposiciones en materia de } \\
\text { organización }\end{array}$ & $\begin{array}{l}\text { Organisational } \\
\text { arrangements }\end{array}$ & $\begin{array}{l}\text { Dispositions relatives à } \\
\text { l'organisation }\end{array}$ \\
\hline Disposición legal & Statutory provision & Disposition statutaire \\
\hline Disposición reglamentaria & Regulation & Réglementation \\
\hline Duración de la pena & Length of the sentence & Durée de la peine \\
\hline Ejecución & Enforcement & Exécution \\
\hline Ejecución de una pena & $\begin{array}{l}\text { Execution of a custodial } \\
\text { sentence }\end{array}$ & Exécution d'une peine \\
\hline En comisión de servicios de & On secondment from & Détaché par \\
\hline En el marco de & Within the framework of & Dans le cadre de \\
\hline
\end{tabular}


ENTREC ULTURAS Número 2. ISSN: 1989-5097. Fecha de public ación: 27-12-2010

\begin{tabular}{|c|c|c|}
\hline En lo sucesivo & Hereinafter & Ci-après \\
\hline En virtud de & By virtue of & En vertu de \\
\hline Enjuiciamiento criminal & Criminal prosecution & Poursuite pénale \\
\hline Entrada en vigor & Entry into force & Entrée en vigueur \\
\hline Entregar & To surrender & Remettre \\
\hline Estado miembro & Member State & État membre \\
\hline Estado miembro emisor & Issuing Member State & État membre d'émission \\
\hline Estado requirente & Requesting State & État requérant \\
\hline Estafa & Swindling & Escroquerie \\
\hline Eurojust & Eurojust & Eurojust \\
\hline Europol & Europol & Europol \\
\hline $\begin{array}{l}\text { Explotación sexual de los } \\
\text { niños y pornografía infantil }\end{array}$ & $\begin{array}{l}\text { Sexual exploitation of } \\
\text { children and child } \\
\text { pornography }\end{array}$ & $\begin{array}{l}\text { Exploitation sexuelle des } \\
\text { enfants } \\
\text { pédopornographie }\end{array}$ \\
\hline Extraterritorialidad & Extraterritorality & Extraterritorialité \\
\hline $\begin{array}{l}\text { Falsificación de } \\
\text { documentos administrativos } \\
\text { y tráfico de documentos } \\
\text { falsos }\end{array}$ & $\begin{array}{l}\text { Forgery of administrative } \\
\text { documents and trafficking } \\
\text { therein }\end{array}$ & $\begin{array}{l}\text { Falsification de documents } \\
\text { administratifs et traffic de } \\
\text { faux }\end{array}$ \\
\hline $\begin{array}{l}\text { Falsificación de medios de } \\
\text { pago }\end{array}$ & $\begin{array}{l}\begin{array}{l}\text { Forgery of means of } \\
\text { payment }\end{array} \\
\end{array}$ & $\begin{array}{l}\text { Falsification de moyens de } \\
\text { paiement }\end{array}$ \\
\hline Falsificación de moneda & $\begin{array}{l}\text { Counterfeiting of } \\
\text { currency }\end{array}$ & Faux monnayage \\
\hline Fecha de expiración & Expiry date & - \\
\hline $\begin{array}{lll}\text { Formas gaves de } \\
\text { delincuencia }\end{array}$ & Serious crime & $\begin{array}{lll}\begin{array}{l}\text { Formes } \\
\text { criminalité }\end{array} & \text { graves de } \\
\end{array}$ \\
\hline Formulario & Form & Formulaire \\
\hline Funcionarios de enlace & Liaison officers & Officiers de liaison \\
\hline Funcionarios participantes & Participating officials & Agents participant \\
\hline Garantías jurídicas & Legal guarantees & Garanties juridiques \\
\hline Hecho en & Done at & Fait à \\
\hline Homicidio voluntario & Murder & Homicide volontaire \\
\hline Impresiones dactilares & Fingerprints & Empreinte digitale \\
\hline Incendio voluntario & Arson & Incendie volontaire \\
\hline Información & Information & Renseignement \\
\hline Información facultativa & Optional information & Informations facultatives \\
\hline Infracción & Offence & Infraction \\
\hline Infracciones castigadas & Punishable offences & Infractions punies \\
\hline Intereses financieros & Financial interests & Intérêts financiers \\
\hline $\begin{array}{l}\text { Intervención y entrega de } \\
\text { objetos }\end{array}$ & $\begin{array}{l}\text { Seizure and handing over } \\
\text { of property }\end{array}$ & Saisie et remise d'objets \\
\hline Jurisdicción & Jurisdiction & Juridiction \\
\hline Llevar a cabo una actuación & To carry out an operation & Mener une opération \\
\hline Llevar a cabo una tarea & To carry out a task & Effectuer une mission \\
\hline Locales destinados & Office accommodation & Bureaux \\
\hline
\end{tabular}


ENTRECULTURAS Número 2. ISSN: 1989-5097. Fecha de public a ción: 27-12-2010

\begin{tabular}{|c|c|c|}
\hline & & \\
\hline $\begin{array}{l}\text { Medida de seguridad } \\
\text { privativa de libertad }\end{array}$ & Detention order & $\begin{array}{l}\text { Mésure de sûreté privative } \\
\text { de liberté }\end{array}$ \\
\hline Medidas de clemencia & Measures of clemency & Mesures de clémence \\
\hline Motu proprio & Proprio motu & De sa propre initiative \\
\hline $\begin{array}{l}\text { Normas específicas de } \\
\text { protección de datos }\end{array}$ & Data protection rules & $\begin{array}{l}\text { Reglès particulières en } \\
\text { matière de protection des } \\
\text { données }\end{array}$ \\
\hline Notificar por carta & To inform by letter & Notifier par une lettre \\
\hline Número de seguridad social & Social security number & Numéro de securité sociale \\
\hline $\begin{array}{l}\text { Número del documento } \\
\text { nacional de identidad }\end{array}$ & National register number & $\begin{array}{l}\text { Numéro au registre } \\
\text { national }\end{array}$ \\
\hline Orden de embargo & Free & Décision de gel \\
\hline Ordenamiento jurídico & Leg: & Système juridique \\
\hline Partes & Parties & Pers \\
\hline $\begin{array}{l}\text { Partes en el acuerdo } \\
\text { Partes del acuerdo }\end{array}$ & Parties to the agreement & Parties à l'accord \\
\hline $\begin{array}{l}\text { Participar en } \\
\text { investigación penal }\end{array}$ & $\begin{array}{l}\text { To participate in a } \\
\text { criminal investigation }\end{array}$ & $\begin{array}{l}\text { Participer à une enquête } \\
\text { pénale }\end{array}$ \\
\hline $\begin{array}{l}\text { Pena o medida de seguridad } \\
\text { privativas de libertad de } \\
\text { carácter perpetuo }\end{array}$ & $\begin{array}{l}\text { Custodial life sentence or } \\
\text { Lifetime detention order }\end{array}$ & $\begin{array}{l}\text { Peine ou mesure de sûreté } \\
\text { privatives de liberté à } \\
\text { caractère perpétuel }\end{array}$ \\
\hline Pena que resta por cumplir & $\begin{array}{l}\text { Remaining sentence to be } \\
\text { served }\end{array}$ & Peine restant à purger \\
\hline Persona condenada & cted person & he condamnée \\
\hline Persona de contacto & Cor & he à contacter \\
\hline Persona física & & ysique \\
\hline Persona jurídica & & Per \\
\hline Persona mencionada & $\mathrm{Abc}$ & he susmentionnée \\
\hline Persona sospechosa & Suspected person & Personne soupçonnée \\
\hline $\begin{array}{lcc}\text { Pertenencia } & \text { a } & \text { una } \\
\text { organización delictiva } & \\
\end{array}$ & $\begin{array}{l}\text { Participation in a criminal } \\
\text { organisation }\end{array}$ & $\begin{array}{l}\text { Participation à une } \\
\text { organisation criminelle }\end{array}$ \\
\hline Práctica & & Pratique \\
\hline Presentación de la solicitud & Submission of request & $\begin{array}{l}\text { Présentation } \\
\text { demande }\end{array}$ \\
\hline Presentar un recurso & nit an appeal & Introduire un recours \\
\hline Procesos penales & al proceedings & are pénale \\
\hline Productos del delito & Proceeds & Produits du crime \\
\hline Protocolo & Prot & Protocole \\
\hline Racismo & Racism & Racisme \\
\hline Red Judicial Europea & $\begin{array}{l}\text { European } \\
\text { network }\end{array}$ & Réseau judiciaire européen \\
\hline Relación de condenas & Statement of convictions & Revevé des condamnations \\
\hline Representante & Representative & Représentant \\
\hline Representante & Representative & Représentant de l'autorité \\
\hline
\end{tabular}


ENTREC ULTURAS Número 2. ISSN: 1989-5097. Fecha de public ación: 27-12-2010

\begin{tabular}{|c|c|c|}
\hline autoridad competente & competent authority & compétente \\
\hline Resolución de decomiso & Confiscation order & Décision de confiscation \\
\hline $\begin{array}{lll}\begin{array}{l}\text { Resolución } \\
\text { rebeldía }\end{array} & \text { dictada en } \\
\end{array}$ & $\begin{array}{l}\text { Decision rendered in } \\
\text { absentia }\end{array}$ & $\begin{array}{l}\text { Décision rendue par } \\
\text { défaut }\end{array}$ \\
\hline $\begin{array}{l}\text { Resolución judicial ejecutiva } \\
\text { del igual fuerza }\end{array}$ & $\begin{array}{l}\text { Judicial decision having } \\
\text { the same effect }\end{array}$ & $\begin{array}{l}\text { Décision judiciaire ayant la } \\
\text { même force }\end{array}$ \\
\hline Respuesta a la solicitud & Reply to the request & Réponse à la demande \\
\hline Revisar & Review & Révision \\
\hline $\begin{array}{lll}\text { Robos organizados } & \text { o a } \\
\text { mano armada } & & \\
\end{array}$ & $\begin{array}{l}\text { Organised or armed } \\
\text { robbery }\end{array}$ & $\begin{array}{l}\text { Vols organisés ou avec } \\
\text { arme }\end{array}$ \\
\hline Sabotaje & Sabotage & Sabotage \\
\hline Secuestro & Kidnapping & Enlèvement \\
\hline $\begin{array}{l}\text { Secuestro de aeronaves y } \\
\text { buques }\end{array}$ & $\begin{array}{l}\text { Unlawful seizure of } \\
\text { Aircraft/ships }\end{array}$ & $\begin{array}{l}\text { Détournement } \\
\text { d'avion/navire }\end{array}$ \\
\hline Sede registral & Registered seat & Siège statutaire \\
\hline Sello oficial & Official stamp & Cachet officiel \\
\hline Sentencia ejecutiva & Enforceable judgement & Jugement exécutoire \\
\hline Será de aplicación & Shall then apply & Sera applicable \\
\hline Solicitar & To request & Demander \\
\hline Solicitar una propuesta & To request a proposal & $\begin{array}{l}\text { Demander } \\
\text { proposition }\end{array}$ \\
\hline $\begin{array}{l}\text { Solicitud de antecedentes } \\
\text { penales }\end{array}$ & $\begin{array}{l}\text { Request for information } \\
\text { extracted from the } \\
\text { criminal record }\end{array}$ & $\begin{array}{l}\text { Demande d'informations } \\
\text { extraites du casier judiciare }\end{array}$ \\
\hline Sujeto a & Subject to & - \\
\hline Terrorismo & Terrorism & Terrorisme \\
\hline Tipificación legal & Legal classification & Qualification légale \\
\hline Titular & Holder & Détenteur \\
\hline Toma de rehenes & Hostage taking & Prise d'otage \\
\hline $\begin{array}{l}\text { Tráfico de vehículos } \\
\text { robados }\end{array}$ & $\begin{array}{l}\text { Trafficking in stolen } \\
\text { vehicles }\end{array}$ & Trafic de véhicules volés \\
\hline $\begin{array}{l}\text { Tráfico ilícito de armas, } \\
\text { municiones y explosivos }\end{array}$ & $\begin{array}{l}\text { Illicit trafficking in } \\
\text { weapons, munitions and } \\
\text { explosives }\end{array}$ & $\begin{array}{l}\text { Trafic illicite d'armes, de } \\
\text { munitions et d'explosifs }\end{array}$ \\
\hline $\begin{array}{l}\text { Tráfico ilícito de bienes } \\
\text { culturales }\end{array}$ & $\begin{array}{l}\text { Illicit trafficking in } \\
\text { cultural goods }\end{array}$ & $\begin{array}{l}\text { Trafic illicite de biens } \\
\text { culturels }\end{array}$ \\
\hline $\begin{array}{l}\text { Tráfico ilícito de especies } \\
\text { animales protegidas y de } \\
\text { especies y variedades } \\
\text { vegetales protegidas }\end{array}$ & $\begin{array}{l}\text { Illicit trafficking in } \\
\text { endangered animal } \\
\text { species and endangered } \\
\text { plant species and varieties }\end{array}$ & $\begin{array}{l}\text { Trafic illicite d'espèces } \\
\text { animales menacées et } \\
\text { d'espèces et d'essences } \\
\text { végétales menacées }\end{array}$ \\
\hline $\begin{array}{l}\text { Tráfico ilícito de } \\
\text { estupefacientes y sustancias } \\
\text { psicotrópicas }\end{array}$ & $\begin{array}{l}\text { Illicit trafficking in } \\
\text { narcotic drugs and } \\
\text { psychotropic substances }\end{array}$ & $\begin{array}{l}\text { Trafic illicite de stupéfiants } \\
\text { et de substances } \\
\text { psychotropes }\end{array}$ \\
\hline $\begin{array}{l}\text { Tráfico ilícito de materiales } \\
\text { radioactivos o r sustancias }\end{array}$ & $\begin{array}{llr}\text { Illicit } & \text { trafficking in } \\
\text { nuclear } & \text { or radioactive }\end{array}$ & $\begin{array}{l}\text { Trafic illicite de matières } \\
\text { nucléaires et radioactives }\end{array}$ \\
\hline
\end{tabular}


ENTRECULTURAS Número 2. ISSN: 1989-5097. Fecha de public ación: 27-12-2010

\begin{tabular}{|c|c|c|}
\hline nucleares & materials & \\
\hline $\begin{array}{l}\text { Tráfico ilícito de órganos y } \\
\text { tejidos humanos }\end{array}$ & $\begin{array}{l}\text { Illicit trade in human } \\
\text { organs and tissue }\end{array}$ & $\begin{array}{l}\text { Trafic illicite d'organes et } \\
\text { de tissues humains }\end{array}$ \\
\hline $\begin{array}{l}\text { Tráfico ilícito de sustancias } \\
\text { hormonales y otros factores } \\
\text { de crecimiento }\end{array}$ & $\begin{array}{l}\text { Illicit trafficking in } \\
\text { hormonal substances and } \\
\text { other growth promoters }\end{array}$ & $\begin{array}{l}\text { Trafic illicite de substances } \\
\text { hormonales et autres } \\
\text { facteurs de croissance }\end{array}$ \\
\hline $\begin{array}{l}\text { Transmisión y recepción } \\
\text { administrativas }\end{array}$ & $\begin{array}{l}\text { Transmission and } \\
\text { administrative reception }\end{array}$ & $\begin{array}{l}\text { Transmission et réception } \\
\text { administrative }\end{array}$ \\
\hline Traslado de pruebas & Transfer of evidence & $\begin{array}{l}\text { Remise des éléments de } \\
\text { preuve }\end{array}$ \\
\hline Trata de seres humanos & $\begin{array}{l}\text { Trafficking in human } \\
\text { beings }\end{array}$ & Traite des êtres humains \\
\hline Tratado & Treaty & Traité \\
\hline Tribunal & Court & Cour \\
\hline Vías de recurso & Legal remedies & Voies de recours \\
\hline Violación & Rape & Viol \\
\hline $\begin{array}{l}\text { Violación de derechos de } \\
\text { propiedad industrial y } \\
\text { falsificación de mercancías }\end{array}$ & $\begin{array}{l}\text { Counterfeiting and piracy } \\
\text { of products }\end{array}$ & $\begin{array}{l}\text { Contrefaçon et piratage de } \\
\text { produits }\end{array}$ \\
\hline Vista & Hearing & Audience \\
\hline Xenofobia & Xenophobia & Xénophobie \\
\hline- & Hereto & À la présente \\
\hline
\end{tabular}

4.4. GLOSARIO DE TÉRMINOS Y FRASEOLOGÍA ADMINISTRATIVOS (INGLÉS-FRANCÉSESPAÑOL)

\begin{tabular}{|l|l|l|}
\hline \multicolumn{1}{|c|}{ INGLÉS } & \multicolumn{1}{c|}{ FRANCÉS } & \multicolumn{1}{c|}{ ESPAÑOL } \\
\hline Address & Adresse & Domicilio \\
\hline Alias & Alias / pseudonyme & $\begin{array}{l}\text { Alias / sobrenombre / } \\
\text { apodo }\end{array}$ \\
\hline Annex & Annexe & Anexo \\
\hline Appendix & Appendice & Apéndice \\
\hline Area/city code & Indicatif de zone ou urbain & Prefijo de ciudad \\
\hline Birth name & Nom à la naissance & Apellido de nacimiento \\
\hline Box & Case & Casilla \\
\hline Contact details & Coordonnées & Señas \\
\hline Country code & Indicatif du pays & Prefijo del país \\
\hline Date of birth & Date de naissance & Fecha de nacimiento \\
\hline Delete if not applicable & Biffer la mention inutile & Táchese lo que no proceda \\
\hline Email / E-mail & $\begin{array}{l}\text { E-mail / Adresse } \\
\text { eléctronique }\end{array}$ & $\begin{array}{l}\text { E-mail } \\
\text { electrónico }\end{array}$ \\
\hline Fax No. & No de télécopie & N. de fax \\
\hline File reference & Référence du dossier & Referencia del expediente \\
\hline First name / Forename & Prénom & Nombre \\
\hline
\end{tabular}


ENTREC ULTURAS Número 2. ISSN: 1989-5097. Fecha de public a ción: 27-12-2010

\begin{tabular}{|l|l|l|}
\hline If applicable & Le cas échéant & En su caso \\
\hline If available & S'il est disponible & Si lo hay \\
\hline If known & Si connu & En caso de conocerse \\
\hline In such case & Dans ce cas & En dicho caso \\
\hline Maiden name & Nom de jeune fille & Apellido de soltera \\
\hline Name & Nom & Apellidos \\
\hline Nationality & Nationalité & Nacionalidad \\
\hline Official language & Langue officielle & Lengua oficial \\
\hline Official name & Nom officiel & Denominación oficial \\
\hline Place of birth & Lieu de naissance & Lugar de nacimiento \\
\hline Post & Fonction & Función \\
\hline Postal address & Adresse postale & Dirección postal \\
\hline Residence & Résidence & Residencia \\
\hline Sex & Sexe & Sexo \\
\hline Signature & Signature & Firma \\
\hline STD code & Préfixe & Prefijo \\
\hline Tel. No. & No de tél. & N. ${ }^{\text {de teléfono }}$ \\
\hline Time limit & Délai & Plazo límite \\
\hline Title & Titre & Cargo \\
\hline To attach & Annexer & Adjuntar \\
\hline To fill in & Remplir & Cumplimentar \\
\hline To tick & Cocher & Marcar \\
\hline To translate & Traduire & Traducir \\
\hline To write & Rédiger & Redactar \\
\hline Where available & Lorsqu'il est connu & Si procede \\
\hline Where applicable & S'il y a lieu & En su caso / Si existiere \\
\hline With respect to & En ce qui concerne & Por lo que respecta a \\
\hline & & \\
\hline
\end{tabular}

\section{REFERENCIAS BIBLIOGRÁFICAS}

\subsection{REFERENCIAS BIBLIOGRÁFICAS EN SOPORTE PAPEL}

Alcaraz Varó, Enrique (2002): El inglés jurídico. Barcelona, Ariel (colección Derecho).

- y Hugues, B. (2002): Legal Translation Explained. Manchester, St. Jerome Pubishing (colección Translation Practices Explained).

BarCeló MarTínez, Tanagua (2010): De testamentorum translatione. Traducción de testamentos franceses al español. Tesis doctoral [inédito]. Universidad de Málaga. BOCQUET, Jean-Claude (2008): La traduction juridique: fondement et méthode. Bruselas, De Boeck (colección Traducto).

Borja AlBI, Anabel (2000): El texto jurídico inglés y su traducción al español. Barcelona, Ariel (colección Ariel Lenguas Modernas). 
FERIA GARCÍA, Manuel. (1999): Traducir para la justicia. Granada, Comares (colección Interlingua, n. ${ }^{\circ}$ ).

LOBATO PATRICIO, Julia (2008): Aspectos deontológicos y profesionales de la traducción jurídica, jurada y judicial. Málaga, Servicio de Publicaciones e Intercambio Científico [CD-ROM].

- (2009): "La traducción jurada, diferencias con la traducción jurídica y judicial". Cadernos Eborenses. Revista Internacional de Traducao, Linguistica e Literatura, n. ${ }^{\circ}$ 1: 421-438.

MAYORAL ASENSIO, Roberto (1997): "La traducción especializada como operación de documentación”, Sendebar, 8-9, 137-153.

- (2003a): "Investigación en traducción jurada" en García Peinado, M. Á. y Ortega Arjonilla, E.: Panorama actual de la investigación en Traducción e Interpretación. Vol. II. Granada, Atrio, 457.

- (2003b): Translating Official Documents. Manchester, St. Jerome Publishing (colección Translation Practices Explained).

- (2004): "Lenguajes de especialidad y traducción especializada. La traducción jurídica", en Gonzalo García, C. y García Yebra, V. (eds.): Manual de documentación y terminología para la traducción especializada. Madrid, Arco Libros, 49-71.

Ortega Arjonilla, Emilio (2005): "La traducción jurídica, jurada y judicial: aspectos teóricos, metodológicos y profesionales" en Borja Albi, A. y Monzó Nebot, E.: Traducción y mediación en las relaciones jurídicas internacionales. Castellón, Universitat Jaume I de Castellón.

- (2004) (dir.): La traducción e interpretación jurídicas en la Unión Europea. Retos para la Europa de los ciudadanos. Granada, Comares (colección Interlingua, n. ${ }^{\circ}$ 75).

PARRA, JAVIER L. (2008): "La interpretación y traducción en el ámbito de la cooperación judicial de la UE" en Ortega Arjonilla (dir.): La traducción e interpretación jurídicas en la Unión Europea. Retos para la Europa de los ciudadanos. Granada, Comares (colección Interlingua, n. ${ }^{\text {7 } 75) . ~}$

SAN Ginés Aguilar, Pedro y Ortega Arjonilla, Emilio (eds.) (1997): Introducción a la traducción jurídica y jurada (inglés-español). Granada, Comares (colección Interlingua, n. ${ }^{\circ}$ ).

ŠArČEVIĆ, Susan (1997/2000): New Approach to Legal Translation. La Haya, Kluwer Law International.

THIRY, Bernard (2009): Terminología y Derecho. Granada, Atrio.

\subsection{REFERENCIAS BIBLIOGRÁFICAS EN SOPORTE ELECTRÓNICO}

Amutio Gómez, Miguel Ángel (ed.) (2007): La construcción de los servicios paneuropeos de Administración electrónica. Madrid, Ministerio de Administraciones Públicas (catálogo general de publicaciones oficiales). 
<www.csi.map.es/csi/pdf/documento_web_IDABC.pdf>

Dueñas JimÉnEZ, Valentín (2006): “El Registro Europeo de Antededentes Penales" en Muñoz de Morales Romero, M.; Arroyo Zapatero, L. A. y Nieto Martín, A. (coord.) (2006): La orden de detención y entrega europea. Ciudad Real, Universidad de Castilla-La Mancha, 187-194.

<http://portal.uclm.es/descargas/idp_docs/doctrinas/duenas_def.pdf $>$

HACIA UNA ESTRATEGIA EUROPEA EN MATERIA DE E-JUSTICIA (JUSTICIA EN LÍNEA) [Comunicación de la Comisión al Consejo, al Parlamento Europeo y al Comité Económico y Social Europeo]

$<$ http://eur-

lex.europa.eu/LexUriServ/LexUriServ.do?uri=com:2008:0329:fin:es:pdf> 